Reselch

\title{
Metformin attenuates olanzapine- induced hepatic, but not peripheral insulin resistance
}

\author{
Gary J Remington ${ }^{1,2,3}$, Celine Teo', Virginia Wilson', Araba Chintoh ${ }^{1,3}$, \\ Melanie Guenette', Zohra Ahsan', Adria Giacca ${ }^{2,4}$ and Margaret K Hahn',2,3 \\ ${ }^{1}$ Centre for Addiction and Mental Health, 250 College Street, Toronto, Ontario, Canada M5T 1R8 \\ ${ }^{2}$ Institute of Medical Science, University of Toronto, 1 King's College Circle, Toronto, Ontario, Canada M5S 1A8 \\ ${ }^{3}$ Department of Psychiatry, University of Toronto, 250 College Street, Toronto, Ontario, Canada M5T 1R8 \\ ${ }^{4}$ Department of Physiology, University of Toronto, 1 King's College Circle, Toronto, Ontario, Canada M5S 1A8
}

\author{
Correspondence \\ should be addressed \\ to M K Hahn \\ Email \\ maggie.hahn@utoronto.ca
}

\begin{abstract}
Antipsychotics (APs) are linked to diabetes, even without weight gain. Whether anti-diabetic drugs are efficacious in reversing the direct effects of APs on glucose pathways is largely undetermined. We tested two metformin (Met) doses to prevent impairments seen following a dose of olanzapine (Ola) $(3 \mathrm{mg} / \mathrm{kg}$ ); glucokinetics were measured using the hyperinsulinemic-euglycemic clamp (HIEC). Met (150 mg/kg; $n=13$, or $400 \mathrm{mg} / \mathrm{kg} ; n=11$ ) or vehicle (Veh) $(n=11)$ was administered through gavage preceding an overnight fast, followed by a second dose prior to the HIEC. Eleven additional animals were gavaged with Veh and received a Veh injection during the HIEC (Veh/Veh); all others received Ola. Basal glucose was similar across treatment groups. The Met 400 group had significantly greater glucose appearance $\left(R_{a}\right)$ in the basal period (i.e., before Ola, or hyperinsulinemia) vs other groups. During hyperinsulinemia, glucose infusion rate (GINF) to maintain euglycemia (reflective of whole-body insulin sensitivity) was higher in Veh/Veh vs other groups. Met 150/Ola animals demonstrated increased GINF relative to Veh/Ola during early time points of the HIEC. Glucose utilization during hyperinsulinemia, relative to basal conditions, was significantly higher in Veh/Veh vs other groups. The change in hepatic glucose production (HGP) from basal to hyperinsulinemia demonstrated significantly greater decreases in Veh/Veh and Met 150/Ola groups vs Veh/Ola. Given the increase in basal $R_{a}$ with Met 400, we measured serum lactate (substrate for HGP), finding increased levels in Met 400 vs Veh and Met 150. In conclusion, Met attenuates hepatic insulin resistance observed with acute Ola administration, but fails to improve peripheral insulin resistance. Use of supra-therapeutic doses of Met may mask metabolic benefits by increasing lactate.
\end{abstract}

\section{Key Words}

- atypical antipsychotics

- insulin resistance

- metformin

- olanzapine

- diabetes
Journal of Endocrinology (2015) 227, 71-81

\section{Introduction}

Antipsychotics (APs) remain the cornerstone of treatment for schizophrenia (Canadian Psychiatric Association 2005). However, their use is also associated with significant concerns in terms of metabolic side effects; high rates of metabolic syndrome, dyslipidemias, weight gain and glucose dysmetabolism have been reported (Goff et al. 2005, Newcomer 2005). While weight gain associated with APs remains a major risk factor for type 2 diabetes (DM2)

Published by Bioscientifica Ltd 
(Pi-Sunyer 1993), there is growing evidence, both clinical and preclinical, indicating increased liability for glucose dysregulation independent of illness-related factors or weight increases (Ader et al. 2005, Houseknecht et al. 2007, Chintoh et al. 2009, Vidarsdottir et al. 2010a, Teff et al. 2013, Hahn et al. 2014). In this regard, our own work from preclinical rodent models consistently supports pronounced, direct effects on insulin sensitivity (peripheral and hepatic) following acute dosing of specific AP agents (e.g., risperidone, olanzapine (Ola) or clozapine) (Chintoh et al. 2008, 2009). From a clinical perspective, acute or 'direct' effects are supported by reports of diabetic ketoacidosis occurring shortly after initiation of AP drugs in absence of notable weight changes (Guenette et al. 2013), as well as studies that suggest a risk of glucose dysregulation independently of weight gain (Newcomer et al. 2002, Henderson et al. 2005, Ebdrup et al. 2014). These observations support the notion that acute mechanisms can lead to glucose dysregulation in the absence of weight gain, but that over time, these can contribute to notable changes in adiposity.

The medical consequences of these side effects are troubling. Patients with serious mental illness, including schizophrenia, have increased rates of cardiovascular disease, which contribute to the twofold increase in the standardized mortality ratio observed in this population (Hennekens et al. 2005, De Hert et al. 2009). Furthermore, the risk of metabolic syndrome is estimated to be twofold higher, and the prevalence of DM2 three- to fivefold higher than the general population (McEvoy et al. 2005, De Hert et al. 2006). Despite these implications, those with serious mental illness and DM2 are insufficiently monitored and undertreated (Frayne et al. 2005, Kreyenbuhl et al. 2006, Goldberg et al. 2007). Moreover, mortality among those with serious mental illness and DM2 is higher than in those diagnosed with DM2 or serious mental illness alone (Jackson et al. 2007, Vinogradova et al. 2010). Clinical studies examining anti-diabetic agents in the context of frank glucose dysregulation in schizophrenia are lacking. As a case in point, to our knowledge, only two clinical studies exist specifically evaluating insulin resistance or impaired glucose tolerance respectively in the context of antipsychotic treatment (Henderson et al. 2009, Smith et al. 2013). Both examined thiazolidinediones and failed to establish significant improvements in indices related to glucose metabolism. Given strong preclinical evidence of direct antipsychotic effects on glucose pathways, independent of and in addition to illness and adiposity, the question remains as to whether anti-diabetic drugs are efficacious in reversing these direct molecular effects.

Metformin (Met), a first-line treatment in the general population for pre-diabetes and DM2 (Canadian Diabetes Association Clinical Practice Guidelines Expert Committee et al. 2013, American Diabetes Association 2014), has been studied as an adjunctive pharmacological intervention for AP-related weight gain. Eleven double blind, randomized, controlled trials have examined Met in this role (Baptista et al. 2006, 2007, Klein et al. 2006, Arman et al. 2008, Wu et al. 2008a,b, 2012, Carrizo et al. 2009, Wang et al. 2012, Chen et al. 2013, Jarskog et al. 2013). Of these, nine examined a surrogate measure of insulin sensitivity, the homeostasis model assessment of insulin resistance (HOMA-IR), with six demonstrating beneficial effects favoring Met (Wu et al. 2008a,b, Carrizo et al. 2009, Wang et al. 2012, Chen et al. 2013, Jarskog et al. 2013). To our knowledge, no studies have specifically examined the effect of Met on glucose metabolism in patients on APs with DM2. In the preclinical literature, a recent rodent study examining effects of three classes of anti-diabetic drugs, including Met, suggested only partial reversal of glucose intolerance induced by Ola during a glucose tolerance test (GTT) (Boyda et al. 2014). In the present investigation, we tested two doses of Met to assess the drug's ability to reverse Ola-induced whole-body insulin resistance; this was done using the hyperinsulinemiceuglycemic clamp (HIEC) technique, the current 'gold standard' allowing the separate determination of drug effects on peripheral and hepatic insulin sensitivity.

\section{Materials and methods}

The Centre for Addiction and Mental Health and University of Toronto Animal Care Committee approved the following protocol. Healthy, male Sprague-Dawley rats (Rattus norvegicus) (12 weeks old, 300-325 g, Harlan, IN, USA) were kept on a $12 \mathrm{~h}$ light: $12 \mathrm{~h}$ darkness cycle and allowed to feed ad libitum. Testing was conducted during the light cycle, with all protocols initiated between 0800 and $0900 \mathrm{~h}$, in free-running rats. Figure 1 provides an overview of the experimental timeline.

\section{Vessel cannulations}

After a 7-day acclimatization period, animals underwent vascular catheterization surgery. Rats were anaesthetized with isoflurane and polyethylene catheters (PE-50, Cay Adams, Boston, MA, USA), with $2.5 \mathrm{~cm}$ of silastic tubing advanced into the right atrium and aortic arch through

Published by Bioscientifica Ltd. 


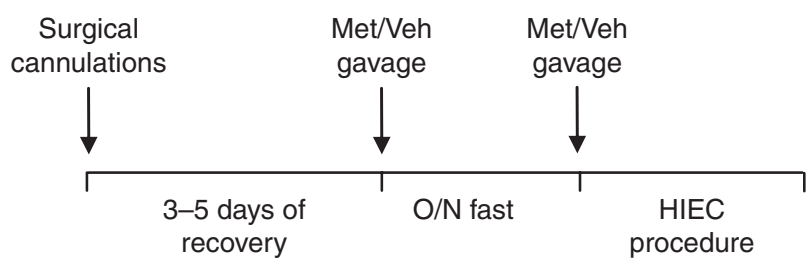

\section{Figure 1}

Experimental timeline. Outline of experimental procedures: metformin (Met); vehicle (Veh); overnight (O/N); hyperinsulinemic-euglycemic clamp (HIEC).

the jugular vein and carotid artery respectively. The catheter lines were externalized dorsally. Buprenorphine $(0.3 \mathrm{mg} / \mathrm{kg})$ (Reckitt Benkiser Healthcare Ltd, Berkshire, UK) was administered for post-operative analgesia and animals were allowed 3-5 days of recovery before the clamping experiments, which were performed in conscious, fasted rats.

\section{Drug and dose selection}

Ola (Toronto Research Chemicals, Toronto, Canada) was dissolved in $1 \%$ acetic acid buffered with $1 \mathrm{M} \mathrm{NaOH}$ to a $\mathrm{pH}>5.5$. S.c. dosing of Ola $(3 \mathrm{mg} / \mathrm{kg})$ was based on $>70 \%$ $\mathrm{D}_{2}$ brain occupancy, reflecting clinically relevant thresholds for therapeutic efficacy (Kapur et al. 2003), as well as established effects on peripheral and hepatic insulin sensitivity (Chintoh et al. 2008, 2009). Animals were randomly assigned and treated with one of two Met doses $(400 \mathrm{mg} / \mathrm{kg}, n=11 ; 150 \mathrm{mg} / \mathrm{kg}, n=13)$ or vehicle (Veh) $(n=11)$, administered through gavage preceding an overnight fast, followed thereafter by a second dose the morning prior to the HIEC. Eleven rats were additionally gavaged with Veh, and injected with Veh directly preceding hyperinsulinemia $(t=90 \mathrm{~min})(\mathrm{Veh} / \mathrm{Veh} ; n=11)$ to serve as controls. All other animals received Ola at the 90 min time point (Met 400/Ola, $n=11$; Met 150/Ola, $n=13$; Veh/Ola; $n=11$ ). The lower dose of Met (150 $\mathrm{mg} / \mathrm{kg} \times$ two doses, administered $15-16 \mathrm{~h}$ apart) was based on evidence that similar doses improve measures of glucose metabolism in rat models of diabetes (Matthaei et al. 1993, Borst et al. 2000, Cleasby et al. 2004, Yasuda et al. 2004). We also examined a higher dose $(400 \mathrm{mg} / \mathrm{kg} \times$ two doses) based on the possibility of dose-dependent effects on metabolic indices (Suzuki et al. 2002, Hauton 2011).

\section{Hyperinsulinemic-euglycemic clamp}

The goal of the HIEC is a new steady state, of higher-thanfasting (i.e., hyperinsulinemic) insulin levels across groups and without a change in the basal glucose level, which would initiate a counterregulatory response and influence glucose kinetics. Hyperinsulinemia is induced via an i.v. insulin infusion, while the 'euglycemic' clamp is achieved via a variable glucose infusion. The amount of glucose infusion (GINF) rate necessary to 'clamp' the glucose level is a measure of whole body insulin sensitivity. Radioactive glucose tracer infused before and during the clamp can also allow the separate determination of glucose production (or rate of glucose appearance; $R_{a}$ ) and utilization (or rate of disappearance; $R_{d}$ ) by a tracer dilution principle. The suppression of glucose production by insulin during the clamp is a measure of hepatic insulin sensitivity, and the stimulation of glucose utilization during the clamp is a measure of peripheral insulin sensitivity.

Following the overnight fast and gavage with the second dose of Met or Veh, catheter lines were immediately extended to the infusion pumps. Radioactive tracer ([3- $\left.\mathrm{H}^{3}\right]$-glucose, $20 \mu \mathrm{Ci} / \mathrm{ml}$ ) was then infused into the jugular vein for $90 \mathrm{~min}$ prior to the clamp, and throughout the clamp ( $0.4 \mathrm{ml}$ bolus plus $7.5 \mu \mathrm{l} / \mathrm{min}$ infusion) $(t=90$ $180 \mathrm{~min})$. The insulin infusion ( $5 \mathrm{mU} / \mathrm{kg} \times \mathrm{min}$ ) began at $t=90 \mathrm{~min}$, and euglycemia was maintained via exogenous glucose given at a variable rate according to plasma glucose levels determined every $5 \mathrm{~min}$. The exogenous glucose was labeled (specific activity $=48 \mu \mathrm{Ci} / \mathrm{g}$ ) to maintain plasma glucose-specific activity constant, which minimizes errors of estimation of glucose production (Finegood et al. 1987). At onset of the 'clamp' ( $t=90 \mathrm{~min}$ ), animals received a single s.c. dose of Ola $(3 \mathrm{mg} / \mathrm{kg})$ or a corresponding volume of Veh (Veh/Veh). Plasma samples were collected every $10 \mathrm{~min}$ during the 30-min tracer equilibration period before the clamp ( $t=60-90 \mathrm{~min}$ ), and during the clamp following Ola injection ( $t=150-180 \mathrm{~min}$ ). Samples were stored at $-80^{\circ} \mathrm{C}$ for subsequent tracer and insulin analysis. Figure 2 provides an overview of the HIEC procedure.

\section{Plasma assays}

Plasma glucose was measured with the glucose oxidase method (Glucose analyzer GM9; Analox Instruments, Lunenbertg, MA, USA). Plasma radioactivity from $\left[3-{ }^{3} \mathrm{H}\right]$ glucose was determined after deproteinization with $\mathrm{Ba}(\mathrm{OH})_{2}$ and $\mathrm{ZnSO}_{4}$ and subsequent evaporation to remove tritiated water. Insulin was analyzed by RIA specific for rat insulin (Linco Research, St Charles, MO, USA). All assays were run in duplicate.

Published by Bioscientifica Ltd. 
Basal phase

Hyperinsulinemic phase

3- $\left[{ }^{3} \mathrm{H}\right]$ Glucose (tracer infusion)

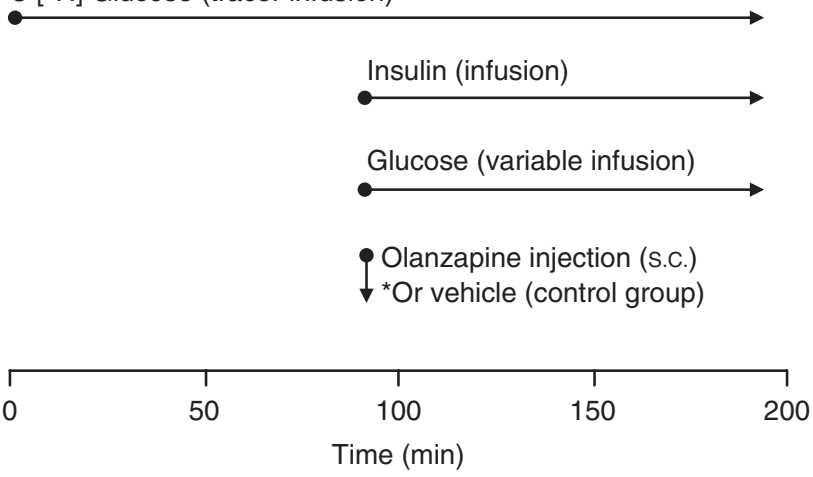

Figure 2

Hyperinsulinemic-euglycemic clamp (HIEC) procedure.

\section{Lactate measurement}

Lactate concentrations were measured in duplicate from plasma samples using an assay kit (Eton Bioscience, San Diego, CA, USA) according to manufacture instructions. The method is based on conversion of lactate and NAD+ by lactate dehydrogenase into pyruvate and NADH. Due to limited remaining plasma volumes, samples across basal time points were combined for each rodent, and analyzed according to treatment group for lactate measurements.

\section{Calculations}

GINF rate was derived based on each animal's weight and GINF pump rate. Glucose turnover (rate of glucose appearance, $\mathrm{R}_{\mathrm{a}}$, determined with $\left[3-{ }^{3} \mathrm{H}\right]$ glucose) was calculated using steady state formulae (Stetten et al. 1951), which also took into account the extra tracer infused with the glucose infusate (Finegood et al. 1987). In the basal state, the total rate of glucose appearance corresponds to the endogenous glucose production. During the clamps, endogenous glucose production was calculated by subtracting the exogenous GINF rate from the total rate of glucose appearance. At steady state, glucose disappearance, $\mathrm{R}_{\mathrm{d}}$, corresponds to the rate of glucose appearance, and at euglycemia, glucose disappearance corresponds to tissue glucose utilization, because renal glucose clearance is zero (Finegood et al. 1987).

\section{Statistical analyses}

A series of mixed models repeated-measures (MMRM) analyses were conducted in order to determine whether glucose, insulin, GINF, $R_{a}$ and $R_{d}$ values changed over the course of the experiment, differed across treatment groups or changed differentially over time across the groups. If a significant time by group interaction was found, indicating that the magnitude of difference between the two treatment groups changed over time, a series of linear contrasts were constructed to further explore the nature of the interaction, with Bonferroni adjustment for multiple comparisons. For lactate measurements, ANOVAs were conducted across treatment groups, followed by post-hoc $t$-tests where applicable, and Bonferroni adjustments for multiple comparisons.

\section{Results}

There were no significant time by group interactions, or group effects for differences in glucose or insulin levels between the four groups (Fig. 3A and B; Table 1). GINF values, reflective of whole-body insulin sensitivity, demonstrated a significant time by group interaction $\left(\mathrm{F}_{3,126}=27.02 ; P=0.006\right)$, leading to further exploration of group effects (Fig. 3C). Post-hoc examination of differences between each pair of groups at each time point, with Bonferroni adjustment for multiple comparisons, demonstrated significantly higher GINF for the Veh/Veh group compared to all other groups throughout the clamp phase, and significantly higher values in the Met 150/Ola group compared to Veh/Ola at the 150- and 170-min time points (Fig. 3C). Examining glucose production, the mixed effect model demonstrated a significant time by group interaction $\left(\mathrm{F}_{24,203}=1.84 ; P=0.012\right)$, driven by differences of group effect during the basal phase (Fig. 4A). Contrasts were used to look at the average group effect during the clamp phase accounting for group effects at the basal phase (defined as the difference in $\mathrm{R}_{\mathrm{a}}$ between clamp and basal phases). Table 1 summarizes statistical testing comparing the effect in $\mathrm{R}_{\mathrm{a}}$ between pairs of groups, with adjustments for multiple comparisons using the Bonferroni method. The decrease in hepatic glucose production (HGP) from basal to clamp phase was significantly greater in both the Veh/Veh and Met 150/Ola groups as compared to Veh/Ola. Comparison of Veh/Ola with Met 400/Ola demonstrated a borderline significant difference $(P=0.0540)$ in between group decreases in $\mathrm{R}_{\mathrm{a}}$. Similar to analyses for $\mathrm{R}_{\mathrm{a}}$, a significant time by group effect was noted for $R_{d}\left(F_{24,203}=3.13\right.$; $P<0.0001)$. To control for differences in basal $R_{d}$, comparison of treatment effect between groups was defined as the change from basal to clamp rates in $\mathrm{R}_{\mathrm{d}}$ (Fig. 4B and Table 1). Table 1 summarizes statistical testing

Published by Bioscientifica Ltd 

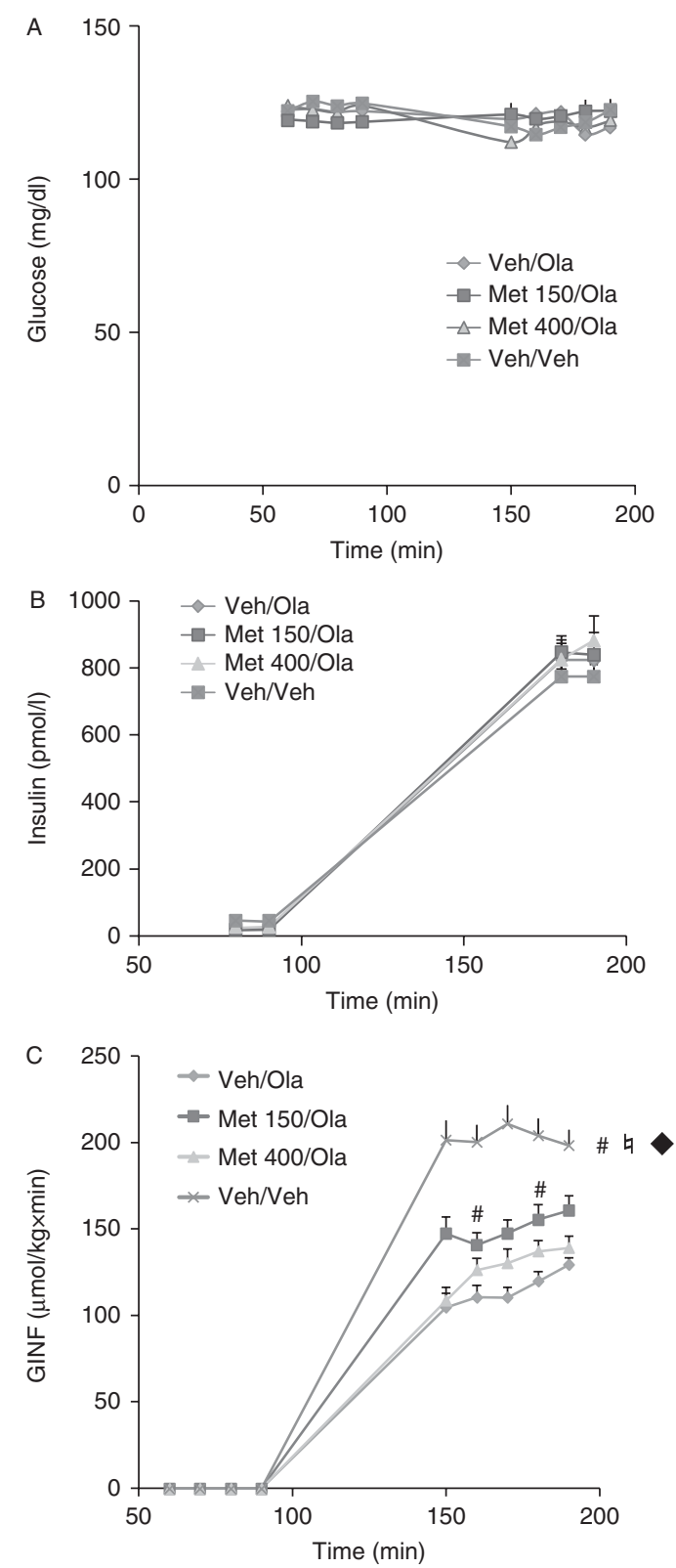

Figure 3

Effect over time, and by treatment group: vehicle + vehicle (Veh/Veh) ( $n=11)$; vehicle + olanzapine (Veh/Ola) $(n=11)$; metformin $150 \mathrm{mg} / \mathrm{kg}+$ olanzapine (Met 150/Ola) ( $n=13)$; metformin $400 \mathrm{mg} / \mathrm{kg}$ + olanzapine (Met $400 / O \mathrm{la}$ ) ( $n=11$ ) on plasma glucose (A), insulin (B) and glucose infusion rate (GINF) (C) during a hyperinsulinemic-euglycemic clamp procedure in male, Sprague-Dawley rats. A significant time $\times$ group interaction was found during the hyperinsulinemic clamp phase $(P<0.05)$ for GINF with post-hoc comparisons and adjustments using the Bonferroni method demonstrating significantly higher GINF in Veh/Veh animals vs all other groups across all time points, and Met 150/Ola differing from Veh/Ola at 150 and $170 \mathrm{~min}$. ${ }^{\#} P<0.05$ vs Veh/Ola; ${ }^{\natural} P<0.05$ vs Met $150 / O l a ;{ }^{\bullet} P<0.05$ vs Met $400 /$ Ola. A full colour version of this figure is available at http://dx.doi.org/10.1530/ JOE-15-0074. comparing the effect in $\mathrm{R}_{\mathrm{d}}$ between pairs of groups, with adjustment for multiple comparisons using the Bonferroni method. Veh/Veh group increases in $R_{d}$ were found to be significantly larger than in all other groups, whereas the other groups did not differ significantly from each other.

To explore the unexpected increase in basal rates of glucose production in the high-dose Met group, we measured basal lactate levels prior to insulin infusion and Ola treatment. We found a significant increase in the high-dose Met group relative to Veh (i.e., Veh/Ola and Veh/Veh) or low-dose Met treatment (Fig. 5).

\section{Discussion}

In the present study, we employed the HIEC to determine if pre-treatment of healthy, male Sprague-Dawley rats with two Met doses $(150 \mathrm{mg} / \mathrm{kg}$ or $400 \mathrm{mg} / \mathrm{kg})$ would attenuate impairments in hepatic and peripheral insulin sensitivity following Ola administration. The HIEC was used to assess both peripheral and hepatic insulin sensitivity, and an acute dosing paradigm of Ola was employed to avoid confounding adiposity changes noted under chronic treatment with this agent. The importance of using acute dosing paradigms to study so-called 'direct effects' of AP medications is highlighted by previous findings in healthy rodents showing that Ola can induce increases in adiposity as early as 1 week into treatment (Albaugh et al. 2011a). Direct AP-induced disruptions in glucose homeostasis may represent a distinguishing factor for patients treated with APs, supporting preclinical investigation of attenuation/prevention of these distinctive disturbances.

In the pre-clinical literature, at least six other studies have examined the effects of various classes of antidiabetic agents (e.g., incretins, sulfonylureas, thiazolidinediones, biguanides) in the context of AP-related glucose perturbations; three studies have examined Met. These reports differ from one another with respect to AP treatment dose and duration, as well methods of assessing glucose metabolism (e.g., stand-alone measures of fasting insulin and glucose, GTTs). In general, incretins (Lykkegaard et al. 2008, Smith et al. 2009) and Met (Adeneye et al. 2011, Boyda et al. 2012, 2014) appear to improve metabolic indices, whereas the data have been more variable for sulfonylureas and thiazolidinediones (Arulmozhi et al. 2006, Boyda et al. 2012, 2014).

The first of the aforementioned studies examining Met (Adeneye et al. 2011) tested single daily administration $(20 \mathrm{mg} / \mathrm{kg})$, comparing treatment with Veh or glibenclamide, during 60 days of administration of

Published by Bioscientifica Ltd. 
Table 1 Comparison of treatment effect between groups. Treatment effect is defined as change from basal to hyperinsulinemic clamp phase $(\Delta)$. $P$ values were adjusted using the Bonferroni method

\begin{tabular}{ll}
\hline Measure & Label \\
\hline $\mathrm{R}_{\mathrm{a}}$ & $(\Delta$ Veh/Ola $)-(\Delta$ Veh/Veh $)$ \\
& $(\Delta$ Met 150/Ola $)-(\Delta$ Veh/Veh $)$ \\
& $(\Delta$ Met 400/Ola $)-(\Delta$ Veh/Veh $)$ \\
& $(\Delta$ Met 150/Ola $)-(\Delta$ Met 400/Ola $)$ \\
& $(\Delta$ Met 150/Ola $)-(\Delta$ Veh/Ola $)$ \\
& $(\Delta$ Met 400/Ola $)-(\Delta$ Veh/Ola $)$ \\
& $(\Delta$ Veh/Ola $)-(\Delta$ Veh/Veh $)$ \\
& $(\Delta$ Met 150/Ola $)-(\Delta$ Veh/Veh $)$ \\
& $(\Delta$ Met 400/Ola $)-(\Delta$ Veh/Veh $)$ \\
& $(\Delta$ Met 150/Ola $)-(\Delta$ Met $400 / O l a)$ \\
& $(\Delta$ Met 150/Ola $)-(\Delta$ Veh/Ola $)$ \\
& $(\Delta$ Met 400/Ola $)-(\Delta$ Veh/Ola $)$ \\
&
\end{tabular}

\begin{tabular}{r} 
Estimate \pm s.E.M \\
\hline $5.014 \pm 1.35$ \\
$-1.459 \pm 1.30$ \\
$1.453 \pm 1.35$ \\
$-2.913 \pm 1.30$ \\
$-6.473 \pm 1.30$ \\
$-3.561 \pm 1.35$ \\
$-10.42 \pm 2.06$ \\
$-12.19 \pm 1.98$ \\
$-11.67 \pm 2.06$ \\
$-0.525 \pm 1.97$ \\
$-1.785 \pm 1.97$ \\
$-1.259 \pm 2.05$
\end{tabular}

\begin{tabular}{c}
\hline DF \\
\hline 203 \\
203 \\
203 \\
203 \\
203 \\
203 \\
203 \\
203 \\
203 \\
203 \\
203 \\
203 \\
\hline
\end{tabular}

\begin{tabular}{c}
\hline $\boldsymbol{t}$ value \\
\hline 3.700 \\
-1.12 \\
1.070 \\
-2.250 \\
-4.990 \\
-2.640 \\
-5.060 \\
-6.170 \\
-5.670 \\
-0.270 \\
-0.900 \\
-0.610 \\
\hline
\end{tabular}

\begin{tabular}{c}
\hline $\operatorname{Pr}>(\boldsymbol{t})$ \\
$<\mathbf{0 . 0 0 0 1}$ \\
0.264 \\
0.284 \\
0.026 \\
$<\mathbf{0 . 0 0 0 1}$ \\
0.009 \\
$<\mathbf{0 . 0 0 0 1}$ \\
$<\mathbf{0 . 0 0 0 1}$ \\
$<\mathbf{0 . 0 0 0 1}$ \\
0.790 \\
0.367 \\
0.541
\end{tabular}

\begin{tabular}{c}
\hline Adjusted $\boldsymbol{P}$ \\
\hline $\mathbf{0 . 0 0 2}$ \\
1.000 \\
1.000 \\
0.105 \\
$<\mathbf{0 . 0 0 0 1}$ \\
0.054 \\
$<\mathbf{0 . 0 0 0 1}$ \\
$<\mathbf{0 . 0 0 0 1}$ \\
$<\mathbf{0 . 0 0 0 1}$ \\
1.000 \\
1.000 \\
1.000 \\
\hline
\end{tabular}

$D F$, degrees of freedom; $\operatorname{Pr}$, probability; $R_{a}$, glucose appearance; $R_{d}$, glucose disappearance.

risperidone $(0.2 \mathrm{mg} / \mathrm{kg}$ once daily). Although significant improvements in all outcome parameters (i.e., weight, fasting glucose, insulin, HbA1c) were observed with Met, failure to take into account Met-related reductions in weight gain could not preclude that improvements in glucose parameters were related to weight loss rather than reversal of direct-risperidone effects on glucose pathways.

Two separate studies by Boyda examined acute Ola (7.5 mg/kg or $15 \mathrm{mg} / \mathrm{kg}$ ) administration, thus avoiding the confounding effects of changes in adiposity. These studies examined the differential effects of Met $(100 \mathrm{mg} / \mathrm{kg}$ or $500 \mathrm{mg} / \mathrm{kg}$ ), rosiglitazone and glyburide, according to single (Boyda et al. 2012) or combination treatment (Boyda et al. 2014) paradigm, on glucose tolerance and insulin sensitivity (HOMA-IR). Met was given at $1100 \mathrm{~h}$ on day 1 , and following an overnight fast, rats received (day 2) a single i.p. injection of Ola ( $7.5 \mathrm{mg} / \mathrm{kg}$ or $15 \mathrm{mg} / \mathrm{kg})$. Sixty min later, saphenous blood was drawn for assessment of insulin sensitivity (HOMA-IR), and a second dose of Met was given, followed by an IP-GTT. A similar protocol was repeated for rosiglitazone and glyburide. Findings suggested partial reversal of glucose intolerance by both rosiglitazone and Met, but not glyburide (Boyda et al. 2012). In the second study, which followed a similar protocol, Met, as well as glyburide, significantly decreased glucose levels during the IP-GTT, whereas rosiglitazone, in contrast to the earlier study, failed to do so. Examination of dual drug combinations demonstrated unexpectedly that the Met-rosiglitazone combination was associated with increased glucose levels relative to single antidiabetic drug treatment (Boyda et al. 2014).

In keeping with pre-existing studies, we have replicated the beneficial effects of Met on indices of glucose metabolism following Ola treatment and, in addition, demonstrated several novel findings. While Met is generally understood to enhance both liver and peripheral insulin sensitivity (Wiernsperger \& Bailey 1999), our data in Ola-treated animals suggest improvements relative to Veh with $150 \mathrm{mg} / \mathrm{kg}$ of Met only in the reduction of glucose production, with no effect on glucose utilization. The lack of effect on glucose disposal might help to explain why the aforementioned studies from Boyda demonstrated only partial reversal of acute Ola-induced glucose intolerance with Met (Boyda et al. 2012, 2014).

Failure of Met to impact peripheral insulin resistance linked to antipsychotic treatment in preclinical models has clinical implications. In rodent models of antipsychotic-induced glucose dysregulation, increased HGP is arguably the most commonly observed perturbation; however, whether or not this is the case in humans is unclear. Of the currently published studies in normalweight healthy volunteers treated with short-term (1-10 days) Ola (Sacher et al. 2008, Vidarsdottir et al. 2010a,b, Albaugh et al. 2011b, Teff et al. 2013, Hahn et al. 2013), two employed the HIEC and separately assessed peripheral and hepatic insulin sensitivity, and both suggested impairments in glucose uptake, but failed to note increases in glucose production (Vidarsdottir et al. 2010a, Teff et al. 2013). Although these findings require replication, they suggest that if peripheral insulin sensitivity is indeed most prominently impacted by APs in humans, use of Met for patients on antipsychotic medications who develop diabetes is open to question. It may be that combination therapy is required to optimally target peripheral insulin resistance. Although thiazolidinediones (insulin sensitizers which act through complementary

Published by Bioscientifica Ltd. 

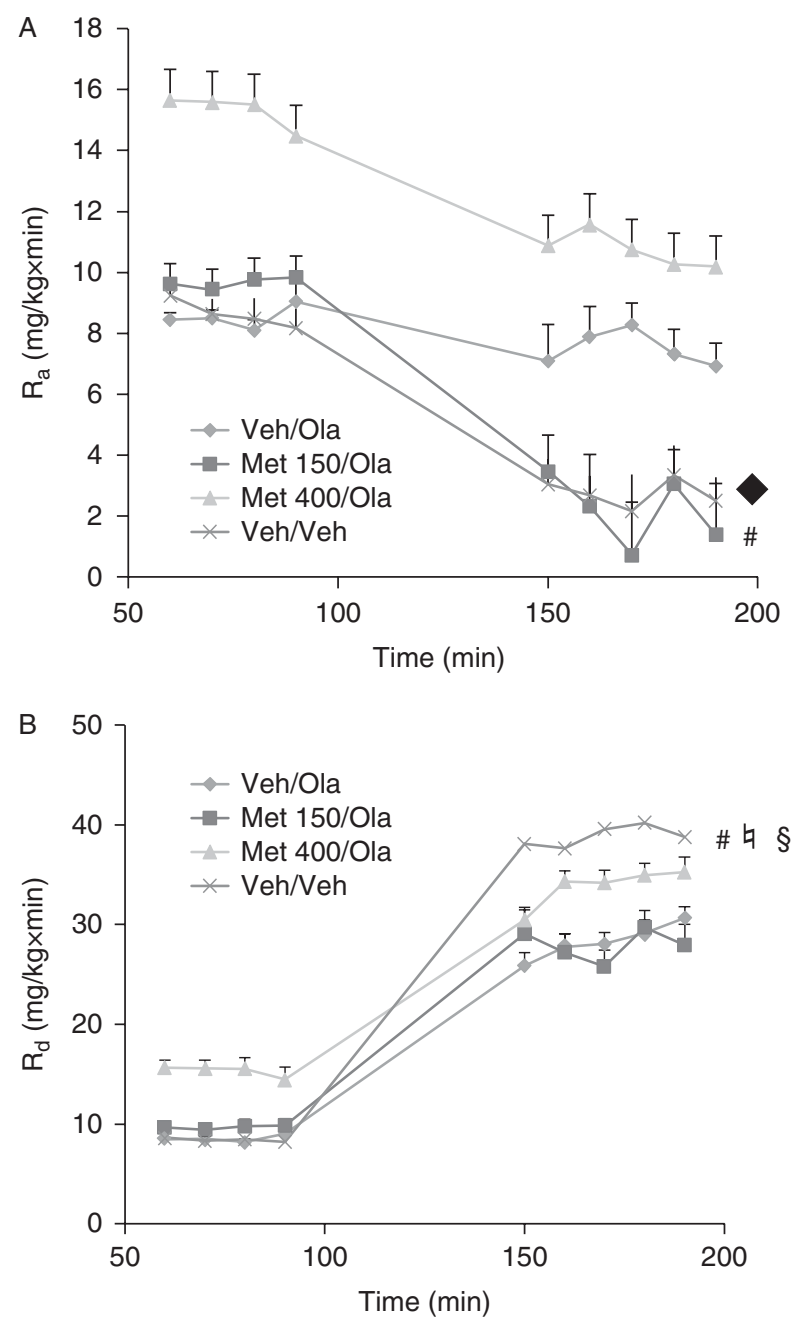

Figure 4

Effect over time, and by treatment group: vehicle + vehicle (Veh/Veh) ( $n=11)$; vehicle + olanzapine (Veh/Ola) $(n=11)$; metformin $150 \mathrm{mg} / \mathrm{kg}+$ olanzapine (Met 150/Ola) $(n=13)$; metformin $400 \mathrm{mg} / \mathrm{kg}$ + olanzapine (Met $400 / O l a)(n=11)$ on rate of glucose appearance $\left(R_{a}\right) /$ production $(A)$ and rate of glucose disappearance $\left(R_{d}\right) / u t i l i z a t i o n(B)$ during a hyperinsulinemic-euglycemic clamp procedure in male Sprague-Dawley rats. Significant time $\times$ group interactions were found for $R_{a}$ and $R_{d}$ and were investigated through post-hoc contrasts to look at the average treatment group effect during the hyperinsulinemic (HI) clamp phase, accounting for differences during the basal phase. 'Treatment effect' was thus defined as the difference between $\mathrm{HI}$ clamp and basal phases (HI clamp-basal) in $\mathrm{R}_{\mathrm{a}}(\mathrm{A})$ or $R_{d}(B)$ and compared between pairs of groups with adjustments using the Bonferroni method. ${ }^{*} P=0.002$ vs Veh/Ola; ${ }^{\#} P<0.0001$ vs Veh/Ola; ${ }^{\natural} P<0.0001$ vs Met $150 / O l a ;{ }^{\S} P<0.0001$ vs Met $400 / O l a$. A full colour version of this figure is available at http://dx.doi.org/10.1530/JOE-15-0074.

pathways to those of Met) would be a rational choice, findings by Boyda et al. (2014) involving Ola related glucose intolerance note a lack of beneficial effect for combination therapy with Met and rosiglitazone. Further studies are therefore required.
Contrary to our working hypothesis, the higher dose of Met $(400 \mathrm{mg} / \mathrm{kg} \times$ two doses) failed to improve insulin sensitivity. Due to an unexpected increase in basal glucose production following high-dose Met, but preceding Ola, as compared to Veh or low-dose Met, we measured plasma lactate. Lactate, a substrate for HGP, was significantly increased in the high-dose Met group relative to both the lower Met dose and Veh. In isolated mitochondria or hepatocytes, Met has been shown to impair mitochondrial respiration by complex 1 inhibition, resulting in increased glycolysis and glucose uptake, decreased liver lactate uptake and decreased use of lactate as a substrate for glucose production (Radziuk et al. 1997, Owen et al. 2000, Otto et al. 2003). However, Met is also known to activate lactate production in the intestine and muscle (Borst \& Snellen 2001), which may hypothetically, in an in vivo system, lead to an excessive gluconeogenic substrate loading, overriding Met-related reductions in lactate usage. Although speculative, the possibility exists that increased hepatic gluconeogenic loading could have

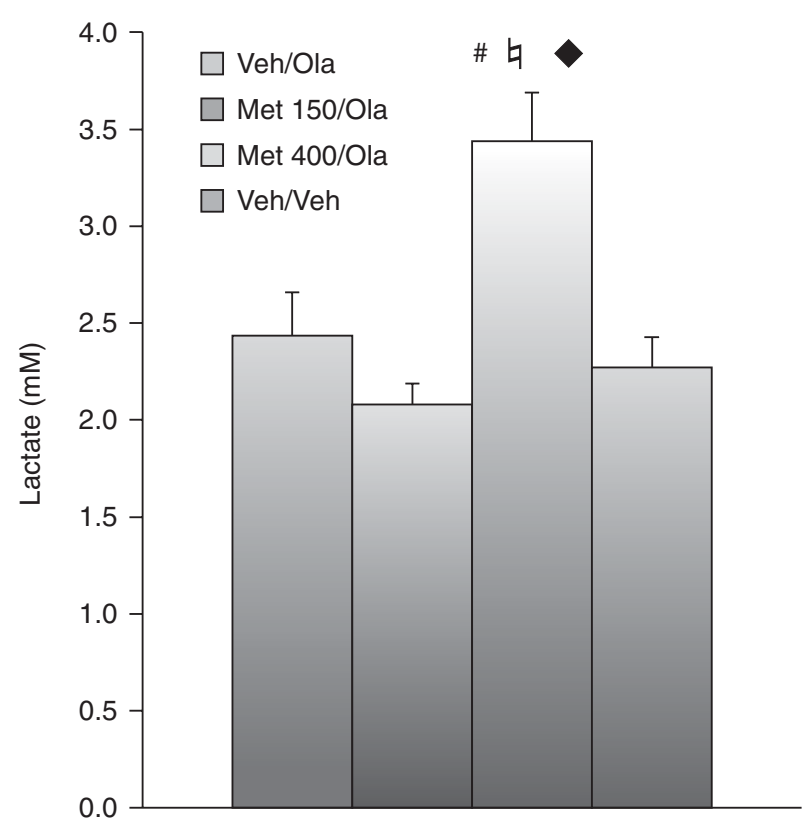

Figure 5

Effect by treatment group: vehicle + vehicle $($ Veh/Veh) $(n=11)$; vehicle + olanzapine** (Veh/Ola) $(n=11)$; metformin $150 \mathrm{mg} / \mathrm{kg}$ + olanzapine (Met 150/Ola) ( $n=13)$; metformin $400 \mathrm{mg} / \mathrm{kg}$ + olanzapine (Met 400/Ola) $(n=11)$ on lactate levels during the basal phase of a hyperinsulinemic-euglycemic clamp procedure; analysis done by ANOVA, followed by Bonferroni adjustments where applicable. ${ }^{\#} P<0.05$ vs Veh/Ola; ${ }^{\natural} P<0.05$ vs Met $150 / O l a ; ~ P<0.05$ vs Veh/Veh. **Lactate was measured preceding olanzapine administration. A full colour version of this figure is available at http://dx.doi.org/10.1530/JOE-15-0074.

Published by Bioscientifica Ltd. 
contributed to the decreased effect of the high Met dose on suppression of HGP following Ola during hyperinsulinemia. Interestingly, there are at least two in vivo studies, administering $300 \mathrm{mg} / \mathrm{kg}$ per day or $1000 \mathrm{mg} / \mathrm{kg}$ per day of Met in rodents, demonstrating respective increases in, or a lack of inhibition of HGP (Dang et al. 2007, Yoshida et al. 2009). It remains unclear why, contrary to our findings, Boyda et al. (2012) found that both the 100 and $500 \mathrm{mg} / \mathrm{kg}$ Met doses significantly decreased glucose intolerance by Ola. However, in their study, the calculated index of insulin resistance in the high-dose Met (HOMA-IR=21.7) appeared to be higher than in the low-dose Met (HOMA-IR=13.9). In addition, the period between administration of the first and second Met doses was longer in the Boyda study (first dose given at $1100 \mathrm{~h}$, vs early evening in the current study). Overall, the clinical relevance of our observation in rodents that a higher Met dose may have masked metabolic benefits in association with an increase in lactate levels is unknown. In humans, the use of higherrange therapeutic doses of Met is unlikely to be of consequence unless elimination of Met is compromised (i.e., renal failure). That said, serious mental illnesses such as schizophrenia and bipolar disorder have been associated with mitochondrial dysfunction and increased lactate levels (Halim et al. 2008, Regenold et al. 2009, Herberth et al. 2011), which raises the unexplored possibility that our patients may require more judicious dosing of Met to obtain maximal benefits. Translation of findings from rodents to clinic may, however, be complicated by genetic factors mediating metabolism and therapeutic action of Met (Shu et al. 2007).

To summarize, in keeping with other preclinical studies, we show that Met can partially mitigate effects of Ola-induced glucose dysregulation, attenuating hepatic insulin resistance but failing to impact peripheral insulin resistance. The high prevalence of DM2 in patients with serious mental illnesses highlights the need for clinical trials that extend beyond weight loss to examine prevention or treatment of glucose dysregulation.

\section{Declaration of interest}

In the past 3 years, G J Remington has received research support from the Canadian Diabetes Association, the Canadian Institutes of Health Research, Medicure, Neurocrine Biosciences, Novartis, Research Hospital FundCanada Foundation for Innovation and the Schizophrenia Society of Ontario. In addition, he has served as a consultant or speaker for Laboratorios Farmacéuticos Rovi, Medicure, Novartis and Synchroneuron. $\mathrm{M} \mathrm{K}$ Hahn has received funding from the Banting Research Foundation, the
Banting and Best Diabetes Centre, and in addition has received speaker's fees from Novartis. The other authors declare they have no conflicts of interests with regard to the work presented in this manuscript.

\section{Funding}

This work was funded through an unrestricted grant from the Centre for Addiction and Mental Health Foundation.

\section{Acknowledgements}

This study was funded by a Centre for Addiction and Mental Health (CAMH) Foundation grant awarded to M K Hahn. The data were presented at the 2014 annual meeting of the Society of Biological Psychiatry and the 2014 annual meeting of the American College of Neuropsychopharmacology.

\section{References}

Adeneye AA, Agbaje EO \& Olagunju JA 2011 Metformin: an effective attenuator of risperidone-induced insulin resistance hyperglycemia and dyslipidemia in rats. Indian Journal of Experimental Biology 49 332-338.

Ader M, Kim SP, Catalano KJ, Ionut V, Hucking K, Richey JM, Kabir M \& Bergman RN 2005 Metabolic dysregulation with atypical antipsychotics occurs in the absence of underlying disease: a placebo-controlled study of olanzapine and risperidone in dogs. Diabetes 54 862-871. (doi:10.2337/diabetes.54.3.862)

Albaugh VL, Judson JG, She P, Lang CH, Maresca KP, Joyal JL \& Lynch CJ $2011 a$ Olanzapine promotes fat accumulation in male rats by decreasing physical activity, repartitioning energy and increasing adipose tissue lipogenesis while impairing lipolysis. Molecular Psychiatry 16 569-581. (doi:10.1038/mp.2010.33)

Albaugh VL, Singareddy R, Mauger D \& Lynch CJ $2011 b$ A double blind, placebo-controlled, randomized crossover study of the acute metabolic effects of olanzapine in healthy volunteers. PLOS ONE 6 e22662. (doi:10.1371/journal.pone.0022662)

American Diabetes Association 2014 Standards of medical care in diabetes 2014. Diabetes Care 37(Suppl 1) S14-S80. (doi:10.2337/dc14-S014)

Arman S, Sadramely MR, Nadi M \& Koleini N 2008 A randomized, doubleblind, placebo-controlled trial of metformin treatment for weight gain associated with initiation of risperidone in children and adolescents. Saudi Medical Journal 29 1130-1134.

Arulmozhi DK, Dwyer DS \& Bodhankar SL 2006 Antipsychotic induced metabolic abnormalities: an interaction study with various PPAR modulators in mice. Life Sciences 79 1865-1872. (doi:10.1016/ j.lfs.2006.06.016)

Canadian Psychiatric Association 2005 Clinical practice guidelines. Treatment of schizophrenia. Canadian Journal of Psychiatry $\mathbf{5 0}$ 7S-57S.

Baptista T, Martinez J, Lacruz A, Rangel N, Beaulieu S, Serrano A, Arape Y, Martinez M, de Mendoza S, Teneud L et al. 2006 Metformin for prevention of weight gain and insulin resistance with olanzapine: a double-blind placebo-controlled trial. Canadian Journal of Psychiatry $\mathbf{5 1}$ 192-196.

Baptista T, Rangel N, Fernandez V, Carrizo E, El Fakih Y, Uzcategui E, Galeazzi T, Gutierrez MA, Servigna M, Davila A et al. 2007 Metformin as an adjunctive treatment to control body weight and metabolic dysfunction during olanzapine administration: a multicentric, doubleblind, placebo-controlled trial. Schizophrenia Research 93 99-108. (doi:10.1016/j.schres.2007.03.029) 
Borst SE \& Snellen HG 2001 Metformin, but not exercise training, increases insulin responsiveness in skeletal muscle of Sprague-Dawley rats. Life Sciences 69 1497-1507. (doi:10.1016/S0024-3205(01)01225-5)

Borst SE, Snellen HG \& Lai HL 2000 Metformin treatment enhances insulin-stimulated glucose transport in skeletal muscle of SpragueDawley rats. Life Sciences 67 165-174. (doi:10.1016/S00243205(00)00612-3)

Boyda HN, Procyshyn RM, Tse L, Hawkes E, Jin CH, Pang CC, Honer WG \& Barr AM 2012 Differential effects of 3 classes of antidiabetic drugs on olanzapine-induced glucose dysregulation and insulin resistance in female rats. Journal of Psychiatry \& Neuroscience 37 407-415. (doi:10.1503/jpn.110140)

Boyda HN, Procyshyn RM, Asiri Y, Wu C, Wang CK, Lo R, Pang CC, Honer WG \& Barr AM 2014 Antidiabetic-drug combination treatment for glucose intolerance in adult female rats treated acutely with olanzapine. Progress in Neuro-Psychopharmacology \& Biological Psychiatry 48 170-176. (doi:10.1016/j.pnpbp.2013.10.006)

Canadian Diabetes Association Clinical Practice Guidelines Expert Committee, Booth G \& Cheng AY 2013 Canadian Diabetes Association 2013 clinical practice guidelines for the prevention and management of diabetes in Canada. Canadian Journal of Diabetes 37(Suppl 1) S1-S3. (doi:10.1016/j.jcjd.2013.01.009)

Carrizo E, Fernandez V, Connell L, Sandia I, Prieto D, Mogollon J, Valbuena D, Fernandez I, de Baptista EA \& Baptista T 2009 Extended release metformin for metabolic control assistance during prolonged clozapine administration: a 14 week, double-blind, parallel group, placebo-controlled study. Schizophrenia Research 113 19-26. (doi:10.1016/j.schres.2009.05.007)

Chen CH, Huang MC, Kao CF, Lin SK, Kuo PH, Chiu CC \& Lu ML 2013 Effects of adjunctive metformin on metabolic traits in nondiabetic clozapine-treated patients with schizophrenia and the effect of metformin discontinuation on body weight: a 24-week, randomized, double-blind, placebo-controlled study. Journal of Clinical Psychiatry $\mathbf{7 4}$ e424-e430. (doi:10.4088/JCP.12m08186)

Chintoh AF, Mann SW, Lam L, Lam C, Cohn TA, Fletcher PJ, Nobrega JN, Giacca A \& Remington G 2008 Insulin resistance and decreased glucose-stimulated insulin secretion after acute olanzapine administration. Journal of Clinical Psychopharmacology 28 494-499. (doi:10.1097/JCP.0b013e318184b4c5)

Chintoh AF, Mann SW, Lam L, Giacca A, Fletcher P, Nobrega J \& Remington G 2009 Insulin resistance and secretion in vivo: effects of different antipsychotics in an animal model. Schizophrenia Research 108 127-133. (doi:10.1016/j.schres.2008.12.012)

Cleasby ME, Dzamko N, Hegarty BD, Cooney GJ, Kraegen EW \& Ye JM 2004 Metformin prevents the development of acute lipid-induced insulin resistance in the rat through altered hepatic signaling mechanisms. Diabetes 53 3258-3266. (doi:10.2337/diabetes.53. 12.3258)

Dang Q, Kasibhatla SR, Reddy KR, Jiang T, Reddy MR, Potter SC, Fujitaki JM, van Poelje PD, Huang J, Lipscomb WN et al. 2007 Discovery of potent and specific fructose-1,6-bisphosphatase inhibitors and a series of orally-bioavailable phosphoramidase-sensitive prodrugs for the treatment of type 2 diabetes. Journal of the American Chemical Society 129 15491-15502. (doi:10.1021/ja0748711)

De Hert M, van Winkel R, Van Eyck D, Hanssens L, Wampers M, Scheen A \& Peuskens J 2006 Prevalence of diabetes, metabolic syndrome and metabolic abnormalities in schizophrenia over the course of the illness: a cross-sectional study. Clinical Practice and Epidemiology in Mental Health: CP \& EMH 2 14. (doi:10.1186/1745-0179-2-14)

De Hert M, Peuskens J \& van Winkel R 2009 Mortality in patients with schizophrenia. Lancet 374 1591; author reply 1592-1593. (doi:10.1016/ S0140-6736(09)61942-5)

Ebdrup BH, Knop FK, Madsen A, Mortensen HB, Sogaard B, Holst JJ, Szecsi PB \& Lublin H 2014 Glucometabolic hormones and cardiovascular risk markers in antipsychotic-treated patients. Journal of Clinical Psychiatry 75 e899-e905. (doi:10.4088/JCP.13m08820)
Finegood DT, Bergman RN \& Vranic M 1987 Estimation of endogenous glucose production during hyperinsulinemiceuglycemic glucose clamps. Comparison of unlabeled and labeled exogenous glucose infusates. Diabetes 36 914-924. (doi:10.2337/diab. 36.8.914)

Frayne SM, Halanych JH, Miller DR, Wang F, Lin H, Pogach L, Sharkansky EJ, Keane TM, Skinner KM, Rosen CS et al. 2005 Disparities in diabetes care: impact of mental illness. Archives of Internal Medicine 165 2631-2638. (doi:10.1001/archinte.165.22.2631)

Goff DC, Sullivan LM, McEvoy JP, Meyer JM, Nasrallah HA, Daumit GL, Lamberti S, D'Agostino RB, Stroup TS, Davis S et al. 2005 A comparison of ten-year cardiac risk estimates in schizophrenia patients from the CATIE study and matched controls. Schizophrenia Research 80 45-53. (doi:10.1016/j.schres.2005.08.010)

Goldberg RW, Kreyenbuhl JA, Medoff DR, Dickerson FB, Wohlheiter K, Fang LJ, Brown CH \& Dixon LB 2007 Quality of diabetes care among adults with serious mental illness. Psychiatric Services 58 536-543. (doi:10.1176/ps.2007.58.4.536)

Guenette MD, Hahn M, Cohn TA, Teo C \& Remington GJ 2013 Atypical antipsychotics and diabetic ketoacidosis: a review. Psychopharmacology 226 1-12. (doi:10.1007/s00213-013-2982-3)

Hahn MK, Wolever TM, Arenovich T, Teo C, Giacca A, Powell V, Clarke L, Fletcher P, Cohn T, McIntyre RS et al. 2013 Acute effects of single-dose olanzapine on metabolic, endocrine, and inflammatory markers in healthy controls. Journal of Clinical Psychopharmacology 33 740-746. (doi:10.1097/JCP.0b013e31829e8333)

Hahn MK, Chintoh A, Remington G, Teo C, Mann S, Arenovich T, Fletcher P, Lam L, Nobrega J, Guenette M et al. 2014 Effects of intracerebroventricular (ICV) olanzapine on insulin sensitivity and secretion in vivo: an animal model. European Neuropsychopharmacology 24 448-458. (doi:10.1016/j.euroneuro.2013.07.011)

Halim ND, Lipska BK, Hyde TM, Deep-Soboslay A, Saylor EM, Herman MM, Thakar J, Verma A \& Kleinman JE 2008 Increased lactate levels and reduced $\mathrm{pH}$ in postmortem brains of schizophrenics: medication confounds. Journal of Neuroscience Methods 169 208-213. (doi:10.1016/ j.jneumeth.2007.11.017)

Hauton D 2011 Does long-term metformin treatment increase cardiac lipoprotein lipase? Metabolism: Clinical and Experimental $6032-42$. (doi:10.1016/j.metabol.2009.12.015)

Henderson DC, Cagliero E, Copeland PM, Borba CP, Evins E, Hayden D, Weber MT, Anderson EJ, Allison DB, Daley TB et al. 2005 Glucose metabolism in patients with schizophrenia treated with atypical antipsychotic agents: a frequently sampled intravenous glucose tolerance test and minimal model analysis. Archives of General Psychiatry 62 19-28. (doi:10.1001/archpsyc.62.1.19)

Henderson DC, Fan X, Sharma B, Copeland PM, Borba CP, Boxill R, Freudenreich O, Cather C, Eden Evins A \& Goff DC 2009 A doubleblind, placebo-controlled trial of rosiglitazone for clozapine-induced glucose metabolism impairment in patients with schizophrenia. Acta Psychiatrica Scandinavica 119 457-465. (doi:10.1111/j.1600-0447.2008. 01325.x)

Hennekens CH, Hennekens AR, Hollar D \& Casey DE 2005 Schizophrenia and increased risks of cardiovascular disease. American Heart Journal 150 1115-1121. (doi:10.1016/j.ahj.2005.02.007)

Herberth M, Koethe D, Cheng TM, Krzyszton ND, Schoeffmann S, Guest PC, Rahmoune H, Harris LW, Kranaster L, Leweke FM et al. 2011 Impaired glycolytic response in peripheral blood mononuclear cells of first-onset antipsychotic-naive schizophrenia patients. Molecular Psychiatry 16 848-859. (doi:10.1038/mp.2010.71)

Houseknecht KL, Robertson AS, Zavadoski W, Gibbs EM, Johnson DE \& Rollema H 2007 Acute effects of atypical antipsychotics on whole-body insulin resistance in rats: implications for adverse metabolic effects. Neuropsychopharmacology 32 289-297. (doi:10.1038/ sj.npp.1301209)

Jackson CT, Covell NH, Drake RE \& Essock SM 2007 Relationship between diabetes and mortality among persons with co-occurring psychotic and

Published by Bioscientifica Ltd. 
substance use disorders. Psychiatric Services 58 270-272. (doi:10.1176/ ps.2007.58.2.270)

Jarskog LF, Hamer RM, Catellier DJ, Stewart DD, Lavange L, Ray N, Golden LH, Lieberman JA \& Stroup TS 2013 Metformin for weight loss and metabolic control in overweight outpatients with schizophrenia and schizoaffective disorder. American Journal of Psychiatry 170 1032-1040. (doi:10.1176/appi.ajp.2013.12010127)

Kapur S, VanderSpek SC, Brownlee BA \& Nobrega JN 2003 Antipsychotic dosing in preclinical models is often unrepresentative of the clinical condition: a suggested solution based on in vivo occupancy. Journal of Pharmacology and Experimental Therapeutics 305 625-631. (doi:10.1124/ jpet.102.046987)

Klein DJ, Cottingham EM, Sorter M, Barton BA \& Morrison JA 2006 A randomized, double-blind, placebo-controlled trial of metformin treatment of weight gain associated with initiation of atypical antipsychotic therapy in children and adolescents. American Journal of Psychiatry 163 2072-2079. (doi:10.1176/appi.ajp. 163.12.2072)

Kreyenbuhl J, Dickerson FB, Medoff DR, Brown CH, Goldberg RW, Fang L, Wohlheiter K, Mittal LP \& Dixon LB 2006 Extent and management of cardiovascular risk factors in patients with type 2 diabetes and serious mental illness. Journal of Nervous and Mental Disease 194 404-410. (doi:10.1097/01.nmd.0000221177.51089.7d)

Lykkegaard K, Larsen PJ, Vrang N, Bock C, Bock T \& Knudsen LB 2008 The once-daily human GLP-1 analog, liraglutide, reduces olanzapineinduced weight gain and glucose intolerance. Schizophrenia Research 103 94-103. (doi:10.1016/j.schres.2008.05.011)

Matthaei S, Reibold JP, Hamann A, Benecke H, Haring HU, Greten H \& Klein HH 1993 In vivo metformin treatment ameliorates insulin resistance: evidence for potentiation of insulin-induced translocation and increased functional activity of glucose transporters in obese ( $\mathrm{fa} / \mathrm{fa}$ ) Zucker rat adipocytes. Endocrinology 133 304-311.

McEvoy JP, Meyer JM, Goff DC, Nasrallah HA, Davis SM, Sullivan L, Meltzer HY, Hsiao J, Scott Stroup T \& Lieberman JA 2005 Prevalence of the metabolic syndrome in patients with schizophrenia: baseline results from the Clinical Antipsychotic Trials of Intervention Effectiveness (CATIE) schizophrenia trial and comparison with national estimates from NHANES III. Schizophrenia Research 80 19-32. (doi:10. 1016/j.schres.2005.07.014)

Newcomer JW 2005 Second-generation (atypical) antipsychotics and metabolic effects: a comprehensive literature review. CNS Drugs 19(Suppl 1) 1-93.

Newcomer JW, Haupt DW, Fucetola R, Melson AK, Schweiger JA, Cooper BP \& Selke G 2002 Abnormalities in glucose regulation during antipsychotic treatment of schizophrenia. Archives of General Psychiatry 59 337-345. (doi:10.1001/archpsyc.59.4.337)

Otto M, Breinholt J \& Westergaard N 2003 Metformin inhibits glycogen synthesis and gluconeogenesis in cultured rat hepatocytes. Diabetes, Obesity \& Metabolism 5 189-194. (doi:10.1046/j.1463-1326. 2003.00263.x)

Owen MR, Doran E \& Halestrap AP 2000 Evidence that metformin exerts its anti-diabetic effects through inhibition of complex 1 of the mitochondrial respiratory chain. Biochemical Journal 348 607-614. (doi:10.1042/bj3480607)

Pi-Sunyer FX 1993 Medical hazards of obesity. Annals of Internal Medicine 119 655-660. (doi:10.7326/0003-4819-119-7_Part_2199310011-00006)

Radziuk J, Zhang Z, Wiernsperger N \& Pye S 1997 Effects of metformin on lactate uptake and gluconeogenesis in the perfused rat liver. Diabetes 46 1406-1413. (doi:10.2337/diab.46.9.1406)

Regenold WT, Phatak P, Marano CM, Sassan A, Conley RR \& Kling MA 2009 Elevated cerebrospinal fluid lactate concentrations in patients with bipolar disorder and schizophrenia: implications for the mitochondrial dysfunction hypothesis. Biological Psychiatry 65 489-494. (doi:10.1016/ j.biopsych.2008.11.010)
Sacher J, Mossaheb N, Spindelegger C, Klein N, Geiss-Granadia T, Sauermann R, Lackner E, Joukhadar C, Muller M \& Kasper S 2008 Effects of olanzapine and ziprasidone on glucose tolerance in healthy volunteers. Neuropsychopharmacology 33 1633-1641. (doi:10.1038/sj. npp.1301541)

Shu Y, Sheardown SA, Brown C, Owen RP, Zhang S, Castro RA, Ianculescu AG, Yue L, Lo JC, Burchard EG et al. 2007 Effect of genetic variation in the organic cation transporter 1 (OCT1) on metformin action. Journal of Clinical Investigation 117 1422-1431. (doi:10.1172/ JCI30558)

Smith GC, Vickers MH, Cognard E \& Shepherd PR 2009 Clozapine and quetiapine acutely reduce glucagon-like peptide- 1 production and increase glucagon release in obese rats: implications for glucose metabolism and food choice behaviour. Schizophrenia Research 115 30-40. (doi:10.1016/j.schres.2009.07.011)

Smith RC, Jin H, Li C, Bark N, Shekhar A, Dwivedi S, Mortiere C, Lohr J, Hu Q \& Davis JM 2013 Effects of pioglitazone on metabolic abnormalities, psychopathology, and cognitive function in schizophrenic patients treated with antipsychotic medication: a randomized double-blind study. Schizophrenia Research 143 18-24. (doi:10.1016/j.schres.2012.10.023)

Stetten D Jr, Welt ID, Ingle DJ \& Morley EH 1951 Rates of glucose production and oxidation in normal and diabetic rats. Journal of Biological Chemistry 192 817-830.

Suzuki M, Odaka H, Suzuki N, Sugiyama Y \& Ikeda H 2002 Effects of combined pioglitazone and metformin on diabetes and obesity in Wistar fatty rats. Clinical and Experimental Pharmacology \& Physiology 29 269-274. (doi:10.1046/j.1440-1681.2002.03644.x)

Teff KL, Rickels MR, Grudziak J, Fuller C, Nguyen HL \& Rickels K 2013 Antipsychotic-induced insulin resistance and postprandial hormonal dysregulation independent of weight gain or psychiatric disease. Diabetes 62 3232-3240. (doi:10.2337/db13-0430)

Vidarsdottir S, de Leeuw van Weenen JE, Frolich M, Roelfsema F, Romijn JA \& Pijl H 2010a Effects of olanzapine and haloperidol on the metabolic status of healthy men. Journal of Clinical Endocrinology and Metabolism 95 118-125. (doi:10.1210/jc.2008-1815)

Vidarsdottir S, Vlug P, Roelfsema F, Frolich M \& Pijl H $2010 b$ Orally disintegrating and oral standard olanzapine tablets similarly elevate the homeostasis model assessment of insulin resistance index and plasma triglyceride levels in 12 healthy men: a randomized crossover study. Journal of Clinical Psychiatry 71 1205-1211. (doi:10.4088/JCP. 08m04654yel)

Vinogradova Y, Coupland C, Hippisley-Cox J, Whyte S \& Penny C 2010 Effects of severe mental illness on survival of people with diabetes. British Journal of Psychiatry 197 272-277. (doi:10.1192/bjp.bp.109. 074674)

Wang M, Tong JH, Zhu G, Liang GM, Yan HF \& Wang XZ 2012 Metformin for treatment of antipsychotic-induced weight gain: a randomized, placebo-controlled study. Schizophrenia Research 138 54-57. (doi:10. 1016/j.schres.2012.02.021)

Wiernsperger NF \& Bailey CJ 1999 The antihyperglycaemic effect of metformin: therapeutic and cellular mechanisms. Drugs 58(Suppl 1) 31-39; discussion 75-82. (doi:10.2165/00003495199958001-00009)

Wu RR, Zhao JP, Guo XF, He YQ, Fang MS, Guo WB, Chen JD \& Li LH $2008 a$ Metformin addition attenuates olanzapine-induced weight gain in drug-naive first-episode schizophrenia patients: a double-blind, placebo-controlled study. American Journal of Psychiatry 165 352-358. (doi:10.1176/appi.ajp.2007.07010079)

Wu RR, Zhao JP, Jin H, Shao P, Fang MS, Guo XF, He YQ, Liu YJ, Chen JD \& Li LH $2008 b$ Lifestyle intervention and metformin for treatment of antipsychotic-induced weight gain: a randomized controlled trial. Journal of the American Medical Association 299 185-193. (doi:10.1001/jama.2007.56-b)

Wu RR, Jin H, Gao K, Twamley EW, Ou JJ, Shao P, Wang J, Guo XF, Davis JM, Chan PK et al. 2012 Metformin for treatment of antipsychotic-induced

Published by Bioscientifica Ltd 
amenorrhea and weight gain in women with first-episode schizophrenia: a double-blind, randomized, placebo-controlled study. American Journal of Psychiatry 169 813-821. (doi:10.1176/appi.ajp.2012. 11091432)

Yasuda N, Inoue T, Nagakura T, Yamazaki K, Kira K, Saeki T \& Tanaka I 2004 Metformin causes reduction of food intake and body weight gain and improvement of glucose intolerance in combination with dipeptidyl peptidase IV inhibitor in Zucker fa/fa rats. Journal of
Pharmacology and Experimental Therapeutics 310 614-619. (doi:10.1124/ jpet.103.064964)

Yoshida T, Okuno A, Tanaka J, Takahashi K, Nakashima R, Kanda S, Ogawa J, Hagisawa Y \& Fujiwara T 2009 Metformin primarily decreases plasma glucose not by gluconeogenesis suppression but by activating glucose utilization in a non-obese type 2 diabetes Goto-Kakizaki rats. European Journal of Pharmacology 623 141-147. (doi:10.1016/j.ejphar. 2009.09.003)

Received in final form 27 August 2015

Accepted 1 September 2015

Accepted Preprint published online 1 September 2015
Published by Bioscientifica Ltd. 